\title{
Hypoxia induces telomerase reverse transcriptase (TERT) gene expression in non-tumor fish tissues in vivo: the marine medaka (Oryzias melastigma) model
}

\author{
Richard MK Yu, Eric XH Chen, Richard YC Kong, Patrick KS Ng, \\ Helen OL Mok and Doris WT Au*
}

Address: Department of Biology and Chemistry, City University of Hong Kong, 83 Tat Chee Avenue, Kowloon, Hong Kong

Email: Richard MKYu - bhrichyu@cityu.edu.hk; Eric XH Chen - ericcxh@cityu.edu.hk; Richard YC Kong - bhrkong@cityu.edu.hk; Patrick KS Ng - arshinghk@yahoo.com.hk; Helen OL Mok - bhholmok@cityu.edu.hk; Doris WT Au* - bhdwtau@cityu.edu.hk

* Corresponding author

Published: II September 2006

BMC Molecular Biology 2006, 7:27 doi:10.1 186/147I-2199-7-27

This article is available from: http://www.biomedcentral.com/I47I-2/99/7/27

(C) 2006 Yu et al; licensee BioMed Central Ltd.

This is an Open Access article distributed under the terms of the Creative Commons Attribution License (http://creativecommons.org/licenses/by/2.0), which permits unrestricted use, distribution, and reproduction in any medium, provided the original work is properly cited.
Received: 06 June 2006

Accepted: II September 2006

\begin{abstract}
Background: Current understanding on the relationships between hypoxia, hypoxia-inducible factor-I (HIF-I) and telomerase reverse transcriptase (TERT) gene expression are largely based on in vitro studies in human cancer cells. Although several reports demonstrated HIF-I- mediated upregulation of the human TERT gene under hypoxia, conflicting findings have also been reported. Thus far, it remains uncertain whether these findings can be directly extrapolated to non-tumor tissues in other whole animal systems in vivo. While fish often encounter environmental hypoxia, the in vivo regulation of TERT by hypoxia in non-neoplastic tissues of fish remains virtually unknown.

Results: The adult marine medaka (Oryzias melastigma) was employed as a model fish in this study. We have cloned and characterized a 326I-bp full-length TERT cDNA, omTERT, which encodes a protein of 1086 amino acids. It contains all of the functional motifs that are conserved in other vertebrate TERTs. Motif $E$ is the most highly conserved showing $90.9-100 \%$ overall identity among the fish TERTs and $63.6 \%$ overall identity among vertebrates. Analysis of the 5 '-flanking sequence of the omTERT gene identified two HRE (hypoxia-responsive element; nt. - 283 and - 892) cores. Overexpression of the HIF-I $\alpha$ induced omTERT promoter activity as demonstrated using transient transfection assays. The omTERT gene is ubiquitously expressed in fish under normoxia, albeit at varying levels, where highest expression was observed in gonads and the lowest in liver. In vivo expression of omTERT was significantly upregulated in testis and liver in response to hypoxia (at 96 $\mathrm{h}$ and $48 \mathrm{~h}$, respectively), where concomitant induction of the omHIF-I $\alpha$ and erythropoietin (omEpo) genes was also observed. In situ hybridization analysis showed that hypoxic induction of omTERT mRNA was clearly evident in hepatocytes in the caudal region of liver and in spermatogonia-containing cysts in testis.

Conclusion: This study demonstrates for the first time, hypoxic regulation of TERT expression in vivo in a whole fish system. Our findings support the notion that hypoxia upregulates omTERT expression via omHIF-I in non-neoplastic fish liver and testis in vivo. Overall, the structure and regulation of the TERT gene is highly conserved in vertebrates from fish to human.
\end{abstract}




\section{Background}

The enzyme telomerase, comprising a telomerase reverse transcriptase (TERT) subunit and a RNA subunit (TR), is ubiquitous from unicellular protozoa to mammals $[1,2]$. In humans, transcriptional regulation of hTERT is the major mechanism of telomerase activation. Hypoxia responsive elements (HREs), to which the hypoxia-inducible factor 1 (HIF-1) binds to regulate transcription of HIF-responsive genes, have been detected in the hTERT promoter $[3,4]$. Current understanding on the mechanistic relationship between hypoxia, hypoxia-inducible factor-1 (HIF-1) and hTERT gene expression is largely based on in vitro studies in human cancer cells. For instance, HIF-1 has been shown to transactivate hTERT expression in human choriocarcinoma cells [4], cervical cancer cells [3] and ovarian carcinoma cells [5]. Hypoxia induction of hTERT expression and subsequent telomerase activity have been reported for solid tumor cells (i.e. ovarian carcinoma and colon adenocarnoma cells) [6]. The HIF-1 $\alpha$ protein has been shown to correlate well with hTERT expression in human placentas [4]. Conversely, Koshiji et al. [7] demonstrated that HIF- $1 \alpha$ downregulates hTERT expression in human colon cancer cells, presumably via the displacement of Myc binding from the hTERT promoter. These conflicting findings suggest multiple mechanistic relationships between hypoxia, HIF- $1 \alpha$ and $h T E R T$ expression in human cancer cells. Yet, it remains virtually unknown whether these findings can be directly extrapolated to non-tumor tissues in other whole animal systems in vivo.

Fish often encounter hypoxia in the aquatic environment, which is a pressing environmental problem worldwide [810]. Gracey et al. [11] used cDNA microarrays to study the hypoxia-induced gene expression profiles of the euryoxic fish, Gillichthys mirabilis, and found that genes encoding glycolytic enzymes and those involved in protein synthesis are downregulated, which support the notion that metabolic depression is an important strategy for survival under hypoxia [12-14]. Interestingly, induction of genes involved in the suppression of cell proliferation and growth has also been observed which could serve as bioindicators of lowered growth during hypoxia. For example, insulin-like growth factor binding protein-1 (IGFBP1) which regulates the availability of insulin-like growth factors in the circulation is involved in growth regulation. The role of HIF-1 in modulation of the IGFBP-1 gene and its involvement in hypoxia-induced growth and developmental retardation have recently been reported in zebrafish $[15,16]$. Although a detailed pattern of response to hypoxia in fish is emerging, it is not clear at what level of hypoxia these responses are initiated and how the various responses are related to each other. So far, we know of no reports on the effect of HIF-1 on TERT transcription in any piscine system. Given the important roles that TERT plays in apoptosis, DNA repair, cell proliferation and growth [17-20], a better understanding of the relationship between hypoxia and fish TERT expression will shed light on the in vivo regulation of fish TERT and its role in adaptive and toxicological responses in fish to hypoxic stress.

To investigate hypoxic regulation of fish TERT expression in vivo, we isolated and cloned the TERT gene (omTERT) from the marine medaka, Oryzias melastigma, and examined its in vivo organ expression patterns in whole fish under normoxia and in response to hypoxic stress. Analysis of omTERT expression by quantitative RT-PCR and in situ hybridization showed significant in vivo induction of omTERT expression in fish livers and testes. Gene transactivation studies using luciferase reporter constructs showed that ectopic expression of omHIF- $1 \alpha$ enhanced omTERT promoter activity in vitro. Taken together, our findings support the notion that hypoxia upregulates omTERT expression via omHIF-1 in non-tumor fish tissues in vivo.

\section{Results}

\section{Isolation and characterization of the OMTERT CDNA}

Using degenerate RT-PCR and RACE, the full-length omTERT CDNA was isolated from O. melastigma. The nucleotide sequence has been deposited in GenBank under accession number DQ286654. The 3624-bp fulllength cDNA contains an open reading frame (ORF) of $3261 \mathrm{bp}$, a 5'-untranslated region (UTR) of $117 \mathrm{bp}$, a 3'UTR of $219 \mathrm{bp}$ and a polyadenylated tail of $27 \mathrm{bp}$. A putative polyadenylation signal (AATAAA) is located $200 \mathrm{bp}$ downstream of the stop codon (TAA) (data not shown). The open reading frame (ORF) of omTERT encodes a polypeptide of 1086 amino acids, with a molecular weight (MW) of $124.5 \mathrm{kDa}$ and a $\mathrm{pI}$ of 9.60. The physical properties of omTERT are very similar to that of the Fugu TERT $($ ORF = 1074 a.a., $M W=122 \mathrm{kDa}, \mathrm{p} I=9.65$; [21]). Pairwise alignment showed that omTERT shares high sequence identity with the TERTs of orange-spotted grouper (63.1\%; Au et al., unpublished observation) and Fugu [Genbank: AAX59693; 61.1\%] and moderate sequence identity with the TERTs of mouse [Genbank: O70372; 34.8\%], human [Genbank: NP 003210; 34.5\%], frog [Genbank: AAG43537; 33.4\%] and chicken [Genbank: AAS75793; 29.1\%].

Multiple sequence alignment indicated that omTERT contains all of the functional motifs that are highly conserved in TERTs from other vertebrate species (Fig. 1; [22-26]). Moreover, sequence comparison of homologus domains from different TERTs indicated that motifs C (58.8\%) and $\mathrm{E}(63.6 \%)$ are most highly conserved (Table 1$)$. These two motifs in omTERT contain signature residues that distinguish telomerase RT from other RTs - the aromatic residue following the two aspartic acid residues in motif $\mathrm{C}$ and the 
Table I: Sequence identity of conserved motifs of omTERT to different vertebrate TERT proteins

\begin{tabular}{|c|c|c|c|c|c|c|c|}
\hline \multirow[t]{2}{*}{ Motif } & \multirow{2}{*}{$\begin{array}{l}\text { Overall cross- } \\
\text { species identity } \\
\text { (\%) }\end{array}$} & \multicolumn{6}{|c|}{ Percent sequence identity of omTERT and: } \\
\hline & & gTERT & fTERT & xTERT & cTERT & hTERT & mTERT \\
\hline \multicolumn{8}{|c|}{$\mathrm{N}$-terminal region } \\
\hline Region v-I & 10.2 & 54.3 & 52.6 & 28.0 & 23.8 & 27.9 & 29.0 \\
\hline Region v-II & 8.3 & 71.9 & 62.5 & 22.5 & 27.8 & 25.0 & 23.1 \\
\hline Region v-III & 25.7 & 68.6 & 62.9 & 42.9 & 37.1 & 45.7 & 37.1 \\
\hline Region v-IV & 25.0 & 75.8 & 69.5 & 43.3 & 42.7 & 41.9 & 42.7 \\
\hline \multicolumn{8}{|c|}{ Central region } \\
\hline T motif & 33.3 & 70.8 & 77.1 & 39.6 & 37.5 & 39.6 & 43.8 \\
\hline \multicolumn{8}{|l|}{ RT motifs: } \\
\hline Motif I & 28.0 & 77.3 & 77.3 & 35.7 & 39.3 & 40.0 & 31.0 \\
\hline Motif 2 & 6.1 & 54.5 & 63.6 & 15.6 & 15.8 & 22.9 & 21.9 \\
\hline Motif A & 29.4 & 82.4 & 70.6 & 50.0 & 47.1 & 50.0 & 41.2 \\
\hline Motif $B^{\prime}$ & 47.1 & 94.1 & 82.4 & 52.9 & 58.8 & 64.7 & 58.8 \\
\hline Motif C & 58.8 & 88.2 & 82.4 & 76.5 & 70.6 & 70.6 & 70.6 \\
\hline Motif $D$ & 34.6 & 76.9 & 80.8 & 57.7 & 53.8 & 57.7 & 53.8 \\
\hline Motif E & 63.6 & 100.0 & 90.9 & 90.9 & 66.7 & 90.9 & 100.0 \\
\hline \multicolumn{8}{|c|}{ C-terminal region } \\
\hline Region v-V & 38.1 & 100.0 & 90.5 & 66.7 & 61.9 & 61.9 & 52.4 \\
\hline Region v-VI & 47.2 & 83.3 & 79.2 & 54.2 & 54.2 & 58.3 & 56.9 \\
\hline Region v-VII & 11.8 & 64.9 & 63.4 & 25.3 & 24.7 & 28.0 & 28.4 \\
\hline
\end{tabular}

tryptophan-X-glycine-X-serine/leucine residues in motif E (Fig. $1 ;$ [27]). These signature sequences along with the TERT-specific T motif indicate that omTERT is a vertebrate TERT. Additionally, conserved amino acid residues known to be indispensable for telomerase activity $[22,23,28]$ are also found in motifs GQ, 1, 2, B', C and E in omTERT (highlighted in bold in Fig. 1). Interestingly, the telomerase activity-determining aspartic acid in motif A of non-teleost TERTs is replaced by glutamic acid in all the fish TERTs. While negligible homology is present among the non-functional flexible linker region (the sequence stretch between regions v-I and v-II; [23]) in the TERTs examined, the length of this linker region in fish TERTs (O. melastigma contains 144 residues; grouper 153 residues; and Fugu 129 residues) are considerably shorter than those of other vertebrate TERTs (for example, frog contains 201 residues, chicken 301 residues, human 155 residues and mouse 160 residues).

\section{In vivo expression and response pattern of omTERT to hypoxia}

Real-time PCR revealed ubiquitous expression of omTERT mRNA in all of the 11 organs examined in both male and female adult fish (Fig. 2), where highest expression was observed in the fish gonads. Moderate omTERT expression was detected in gill, brain, kidney, gut and spleen followed by eye, heart, skin, muscle. omTERT was expressed only very weakly in liver.
We next compared the expression of omTERT mRNA under normoxia and hypoxia in two fish organs showing the highest (gonads) and lowest (liver) endogenous omTERT expression levels. Since a large variation in omTERT expression was found among different fish ovary samples, testes instead of ovaries were used. Upon exposure to hypoxia for $24 \mathrm{~h}$ and $48 \mathrm{~h}$, no significant difference in expression of omTERT (Fig. 3A), omHIF-1 $\alpha$ (Fig. 3B) and the HIF-regulated omEpo gene (Fig. 3C) was observed when compared to normoxic fish testes. Upon exposure to prolonged hypoxia for $96 \mathrm{~h}$, omTERT in testes was induced by $2.2 \pm 0.2$ fold ( $p<0.05$; Fig. $3 \mathrm{~A}$ ) with a concomitant increase in omHIF-1 $\alpha(1.6 \pm 0.1$ fold; $p<0.05$; Fig. 3B) and omEpo (2.2 \pm 0.5 fold; $p<0.05$; Fig. 3C) expression. In liver, omTERT was hypoxically induced as early as $48 \mathrm{~h}(1.8 \pm 0.2$ fold $)$ and the level was sustained until $96 \mathrm{~h}(1.6 \pm 0.1$ fold; $p<0.05$; Fig. $3 \mathrm{~A})$. At these two time points, hypoxic induction of omHIF-1 $\alpha(48 \mathrm{~h}: 1.7 \pm$ 0.2 fold $(p<0.05)$; and 96 h: $1.6 \pm 0.2$ fold $(p<0.05)$; Fig. 3B) and omEpo ( $48 \mathrm{~h}: 2.8 \pm 0.7$ fold $(p<0.05)$; and $96 \mathrm{~h}$ : $1.7 \pm 0.1$ fold $(p=0.08)$; Fig. $3 \mathrm{C}$ ) was also observed in the liver.

In situ hybridization analysis showed that under normoxia, omTERT mRNA was only weakly expressed in the liver parenchyma (Fig. 4A). At $96 \mathrm{~h}$ hypoxia, omTERT expression was induced significantly in the caudal region of liver (Fig. 4B). In testis, omTERT expression was local- 


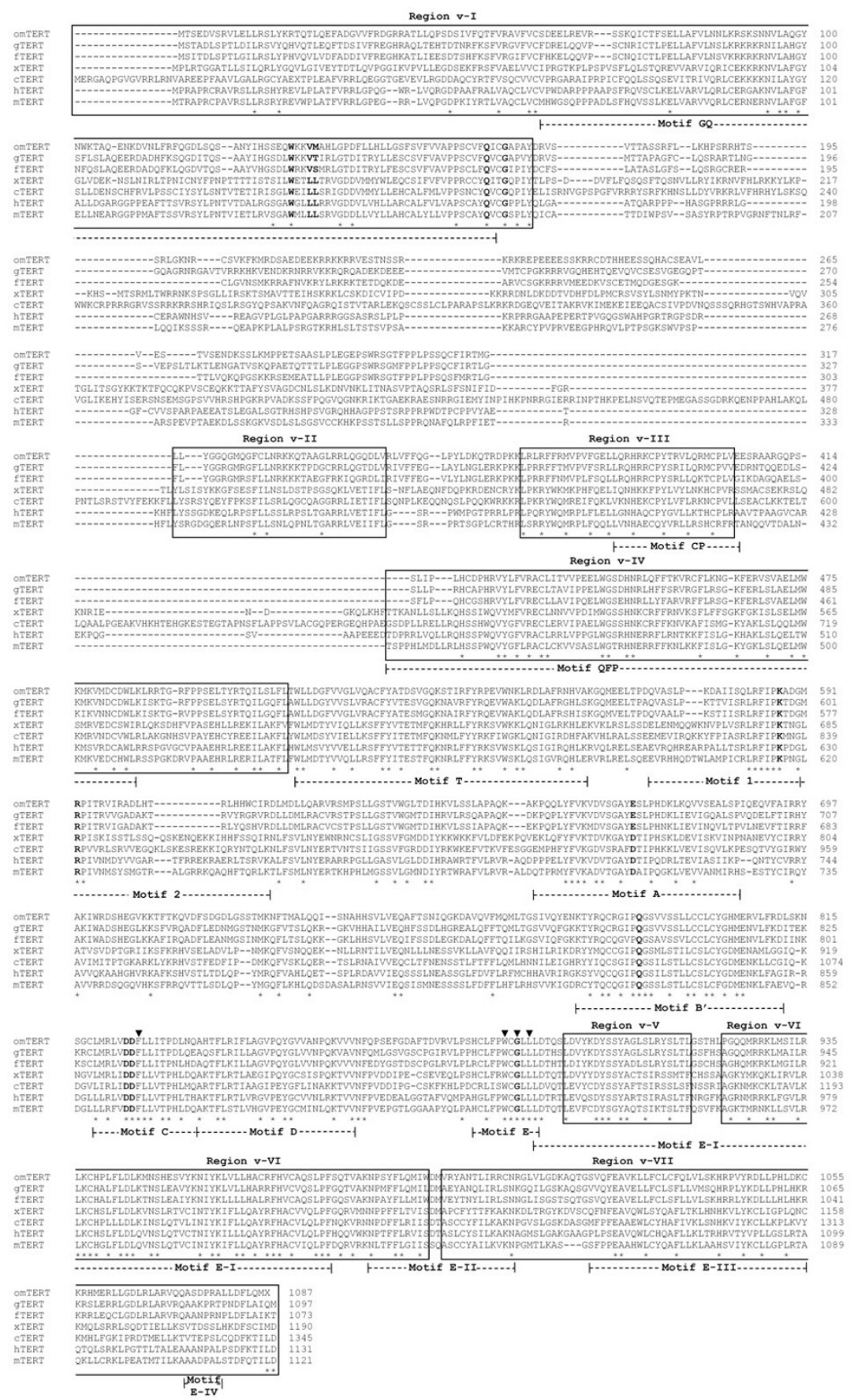

Figure I

Multiple alignment of the deduced amino acid sequence of omTERT with selected vertebrate TERT homologues. TERT proteins from top to bottom are: omTERT (O. melastigma, this study), gTERT (orange-spotted grouper, Epinephelus coioides, unpublished, Genbank: DQ317442), fTERT (Fugu, Genbank: AAX59693), xTERT (Xenopus laevis, Genbank: AAG43537), cTERT (chicken, Genbank: AAS75793), hTERT (human, Genbank: NP 0032I0), mTERT (mouse, Genbank: NP 033380). Number on the right denotes the amino acid position. Identical amino acids shared by all protein sequences are marked with asterisks (*). Dashes (--) indicate gaps inserted for improved alignment. Residues known to be essential for telomerase activity are highlighted in bold. Conserved regions in the v-I to v-VII regions of vertebrate TERTs are labelled. Functional motifs: GQ, CP, QFP, T, I, 2, A, B', C, D, E, E-I, E-II, E-III and E-IV are indicated by dashed lines and labelled underneath. Signature amino acid residues distinguishing TERT from other RTs are indicated by inverted triangles ( $\nabla$ ). 


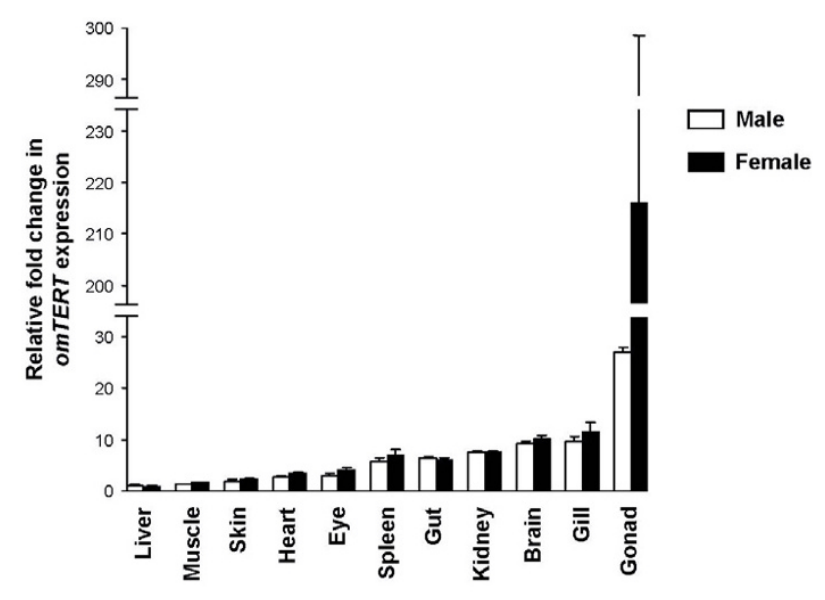

Figure 2

In vivo expression of omTERT mRNA. Expression of omTERT in various $O$. melastigma tissues of male (open bar) and female (solid bar) fish $(n=5)$ were quantified using realtime RT-PCR and normalized against I8S rRNA. Data are presented as mean relative fold changes \pm SEM with respect to expression level in the liver of female fish (arbitrarily set to I).

ized mainly in cysts containing highly proliferative sperm cells (i.e. spermatogonia and spermatocytes) and differentiating spermatids but not in mature spermatozoa (Fig. 4D). Upon exposure to hypoxia for $96 \mathrm{~h}$, cysts containing spermatogonia showed the strongest induction of omTERT expression (Fig. 4E).

\section{omTERT 5'-flanking sequence}

PCR amplification of a StuI Genome Walking library (of O. melastigma) yielded a 3.6-kb genomic fragment which contains 3440-bp of 5'-flanking sequence and 185-bp 5'UTR of the omTERT gene. The sequence has been deposited in GenBank under accession number DQ286655. Similar to the TERT promoters of Fugu, chicken and human $[21,26,29]$, the omTERT 5 '-flanking sequence lacks a canonical TATA box but contains three putative CCAAT boxes near the transcription start site (TSS; at nt positions - 10, - 41 and - 91; Fig. 5). In contrast to hTERT and cTERT, no CPG island is found in the omTERT promoter, which is notably AT-rich $(60 \%)$. Comparison of the omTERT and fTERT 5'-flanking sequences using the PromoterWise program (EMBL-EBI) [30] failed to detect any homologous region of significant sequence identity. Using BLAST, the O. latipes TERT (olTERT) promoter sequence was identified in the medaka genome database [31] (scaffold 3719 at the NIG DNA Sequencing Center, Japan), and a 177-bp region that is conserved in both the omTERT and the O. latipes TERT (olTERT) promoters (ca. $75 \%$ identity) upstream of the TSS was identified. Signifi-
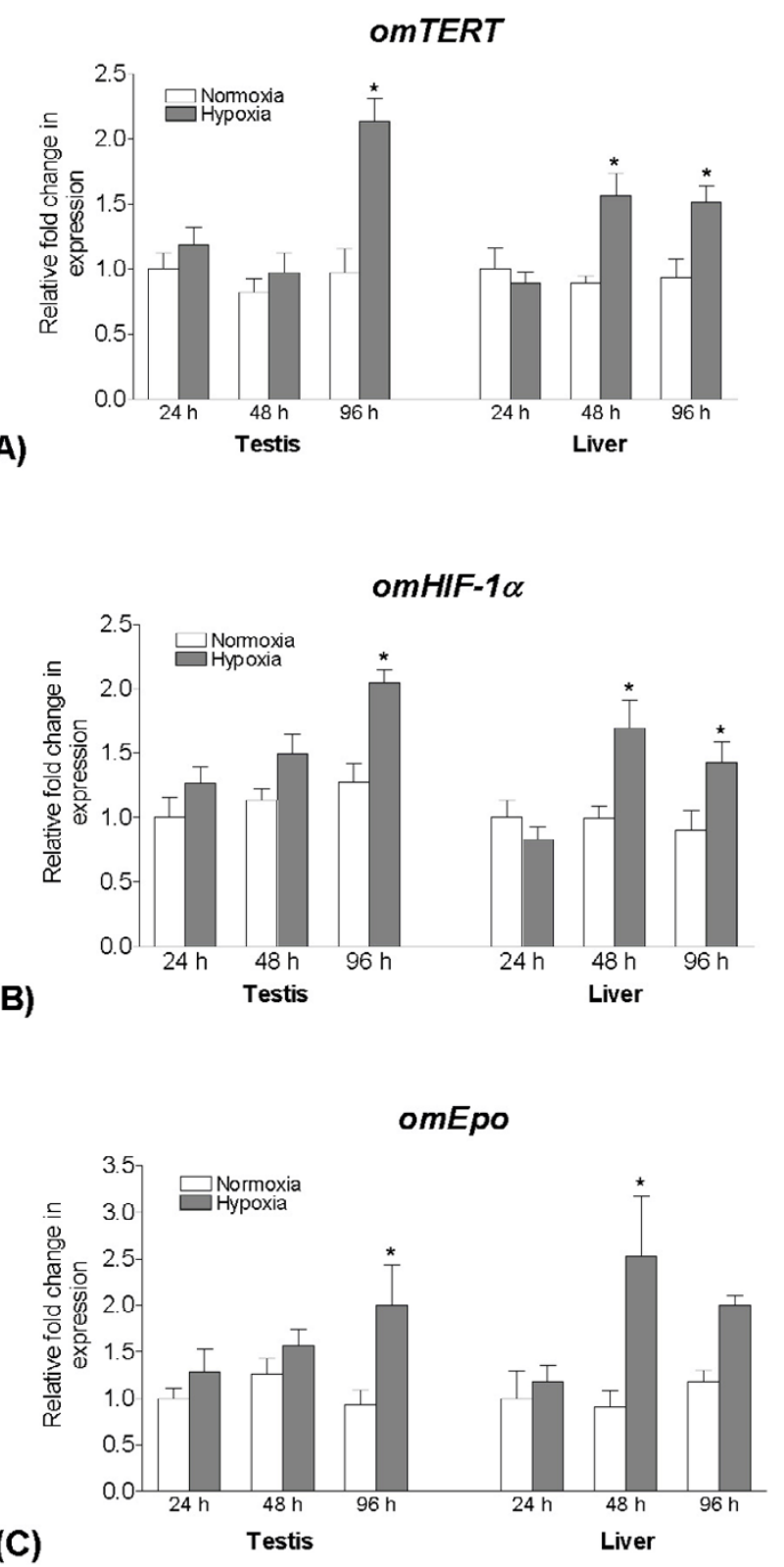

Figure 3

Hypoxic induction of omTERT, omHIF-I $\alpha$ and omEpo expressions in liver and testis of marine medaka in vivo. Male fish $(n=5)$ were exposed to either normoxic (6.4 $\mathrm{mg} \mathrm{O}_{2} \mathrm{~L}^{-1}$ ) or hypoxic (I.8 $\left.\mathrm{mg} \mathrm{O}_{2} \mathrm{~L}^{-1}\right)$ conditions for 24,48 and $96 \mathrm{~h}$. Expression of (A) omTERT, (B) omHIF-I $\alpha$ and (C) omEpo in the livers and testes was quantified using real-time RT-PCR and normalized with I8S rRNA. Data are presented as mean relative fold change \pm SEM with respect to the gene expression level in the normoxic tissue sample at $24 \mathrm{~h}$ (arbitrarily set to I). Asterisk (*) indicates significant difference from the other treatment group $(p<0.05)$.

cant sequence homology (69\%) was also identified in the 5 '-UTRs of the omTERT and olTERT genes. 

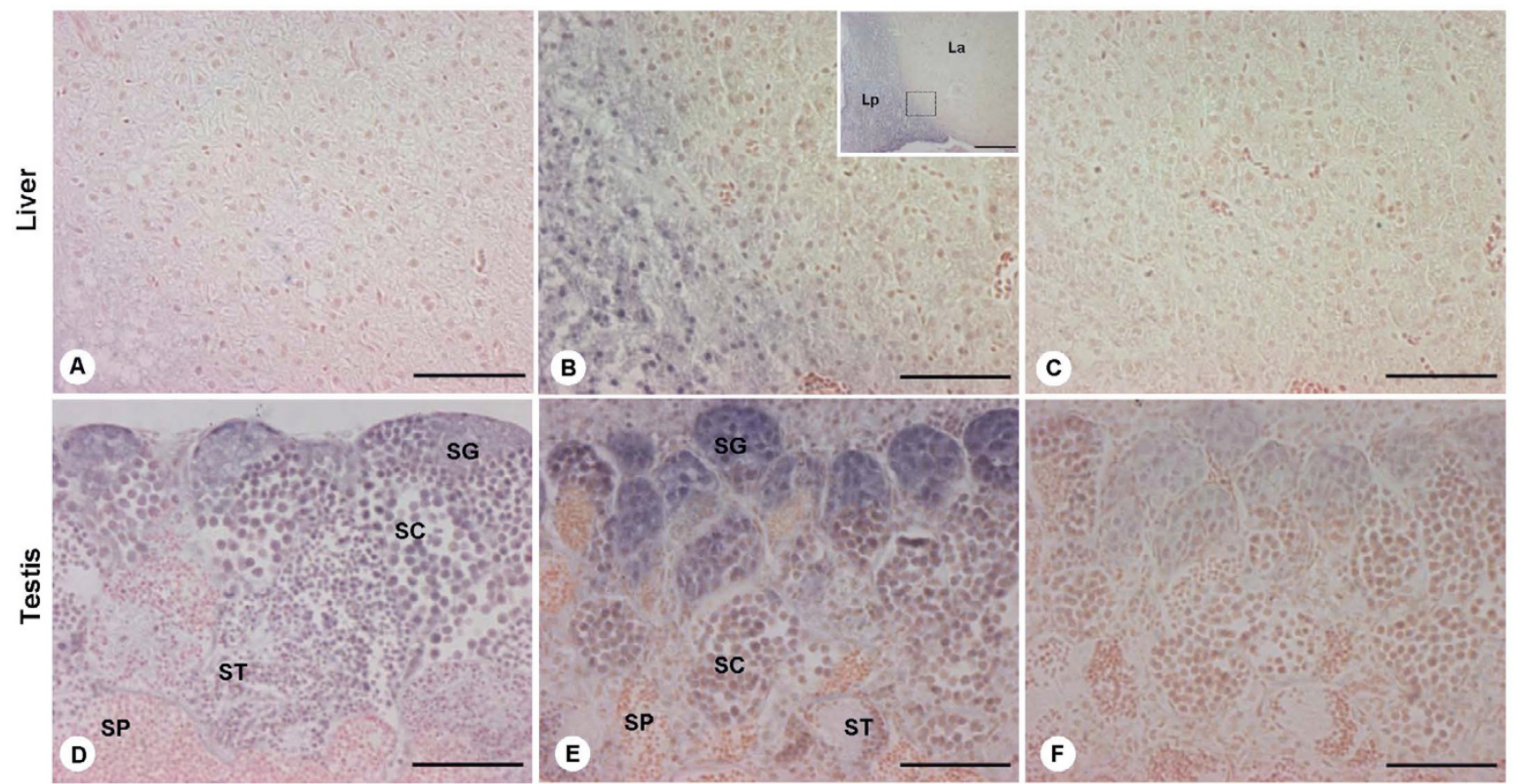

\section{Figure 4}

In situ localization of omTERT mRNA in livers (A-C) and testes (D-F) of marine medaka. (A) Liver under normoxia (6.4 $\left.\mathrm{mg} \mathrm{O}_{2} \mathrm{~L}^{-1}\right)$. Weak expression of omTERT mRNA (blue) is observed in liver parenchyma. (B) Liver exposed to hypoxia (I.8 $\mathrm{mg} \mathrm{O} \mathrm{L}^{-1}$ ) for $96 \mathrm{~h}$. Induced expression of omTERT mRNA (blue) is evident, particularly at the posterior or caudal region of liver (Lp) as compared to the rostal or anterior region (La) (see insert at low magnification). (C) Adjacent liver section of (B) hybridized with an omTERT sense riboprobe as a negative control. (D) Testis under normoxia $\left(6.4 \mathrm{mg} \mathrm{O}_{2} \mathrm{~L}^{-1}\right)$. Expression of omTERT mRNA (blue) is strong in cysts containing spermatogonia (SG) and spermatocyte (SC), moderate in differentiating spermatids (ST) and absent in mature spermatozoa (SP) (red). (E) Testis exposed to hypoxia (I.8 mg $\left.\mathrm{O}_{2} \mathrm{~L}^{-1}\right)$ for $96 \mathrm{~h}$. Induction of omTERT mRNA (blue) is conspicuous in spermatogonia (SG) and less prominent in other testicular cells. (F) Adjacent testis section of $(E)$ hybridized with an omTERT sense riboprobe as a negative control. Scale bars $=50 \mu \mathrm{m}$, except insert of $(\mathrm{b})=200$ $\mu \mathrm{m}$.

To identify potential transcription factor binding sites (TFBSs) in the omTERT promoter, the first 1000-bp sequence upstream of the TSS was analyzed using a filter string-based search supported by the TESS program [32]. Two putative HREs (hypoxia-responsive elements; at nt. 283 and - 892) were identified which contain the exact HRE sequence (ACGTG) as the functional HRE described in the zfIGFBP-1 gene promoter of zebrafish [16]. However, a HIF-1 ancillary sequence (HAS) adjacent to the HRE, that affects hypoxia and HIF-1 responsiveness of the zfIGFBP-1 gene, is not present in the omTERT promoter. Moreover, a single putative HRE core (GCGTG) was also identified in the Fugu TERT promoter [Genbank: AY861384].

Other putative TFBSs of particular interest were also found: AP1 (nt. +11, -42, -92, -617 and -637), SP1 (nt. +6 and -822), NF-1 (nt. -770 and -797), E-box (nt. -893), GATA-1 (nt. +24, -168, -563, -598, -617, -637, -803, -811 and -932), GATA-3 (nt. -335), GATA-4 (nt. -77 and -335),
USF (upstream stimulating factor; nt. -730), c-Myb (nt. $+18,-59,-581$ and -633 ), GR (glucocorticoid receptor; $n t$. $+29,+94,+99,-234,-672,-918$ and -941$)$, PR (progesterone receptor; nt. +94 and -551), AR (androgen receptor; nt. - 19), T3R- $\beta$ (thyroid hormone receptor- $\beta$; nt. -448 and -549), ER (estrogen receptor; nt. -737) and c-Est-2 (nt. 445 and -835) and DRE (dioxin-responsive element; nt. 483). Of these putative TFBSs: AP1, SP1, USF, E-box, and ER are implicated in the regulation of $h T E R T$ transcription $[4,33,34]$.

\section{Induction of omTERT promoter by omHIF-I $\alpha$}

To test the hypothesis that HIF- $1 \alpha$ regulates omTERT transcription, the effect of omHIF-1 $\alpha$ overexpression on luciferase activity driven by $3.5 \mathrm{~kb}$ of omTERT promoter sequence was evaluated in HIF- $1 \alpha$-deficient CHO Ka13 cells. When cells were co-transfected with both pCMVomHIF- $1 \alpha$ and pTERT-luc, luciferase activity was significantly increased by ca. 2-fold when compared with cells transfected with pTERT-luc alone $(p<0.05)$ (Fig. 6). 
-1000 CСTTCTACGGCCCTGTCCAGCTCTCCCAGAATAACCTCCAGTCTCCTGAAATCTCCTCCATGTTCTGGAGA
-929 TTGTGCTGGGAGACACATTAAACCTTCTTGCTGCAGCACGTGTGGATGTTCCATCCTGGAGAAGTTGGACA

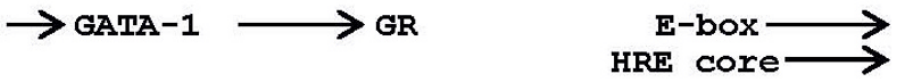

-858 ACCTGTTCAACTTCTGTAGGGTAAGGAACTCCTCATACTGCCAGTAGAGATAACTATCAAGCCAAAATC

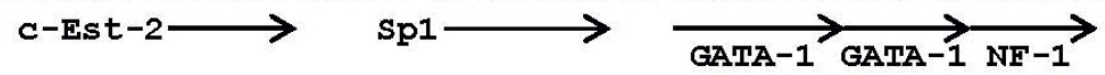

-787 AGCACGAGTGGAAAACCAGCCAAAAAAGATCAAGAGGGAGAAACTTGAAATGACCTCCACATGTAACACCA

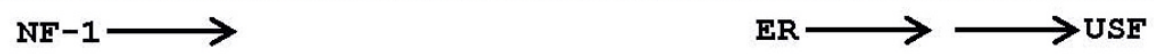

-716 GPCCTGTTGGAGGGTTTCTAATTTTACСACTGAAGTGCACCTGTTGTTAATTCATGAACACCAATACA

-645 GATGAAATTGATTAACGAGGCCCTCAGCTGATTAACCAACAAGAAAATTATCAAACAGGTTTAATTCAATT

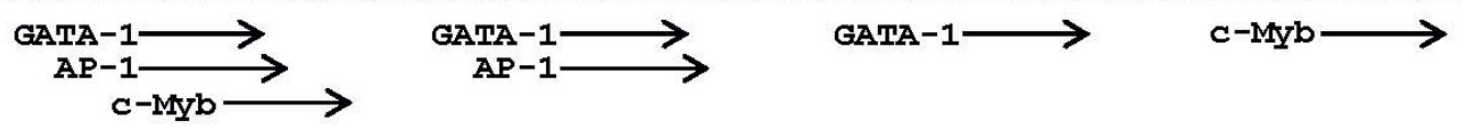

-574 САTGCCAGGTCCGATAAAAAAAGTGTTACTTTAATTTTTGTGAGCAGTGTACATTAATTTGAAAAATGAGA

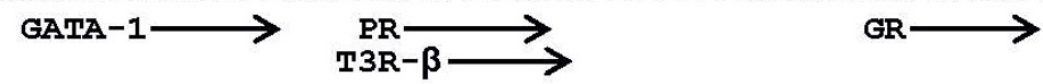

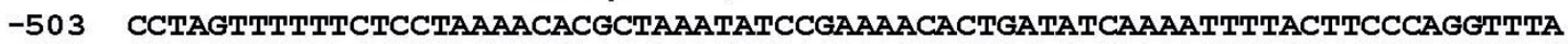

$$
\mathrm{DRE} \longrightarrow \quad \begin{array}{r}
\mathrm{T} 3 \mathrm{R}-\boldsymbol{\beta} \longrightarrow \mathrm{C-ESt-2} \longrightarrow \\
\mathrm{C}
\end{array}
$$

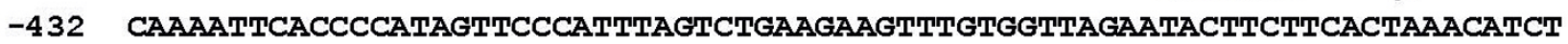

-361 САTACTTGCTTGACTTAAGACAATAAAGATATGTTTAAAAAATGGTGCAAACTTAAATAAAAACATCTATT GATA $-3 /-4 \longrightarrow$

-290 TGTGATGACGTGTAAATGTAATCAACTCAATTTTATTTTATTTATATAGCCCAATATCACAAATCAATTG

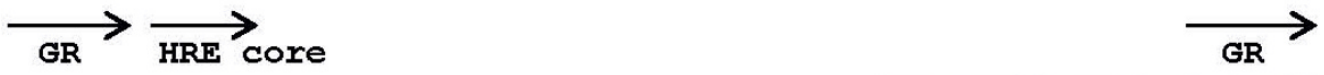

-219 CCTCATTGGGCTTGAAGCAGAAAGTACGACTATGACTTGTATTTATTTTATTTTATCGМATTTATTTTGC GATA-1

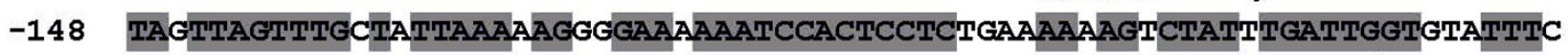
CCAAT-binding factor

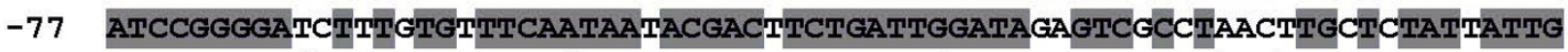

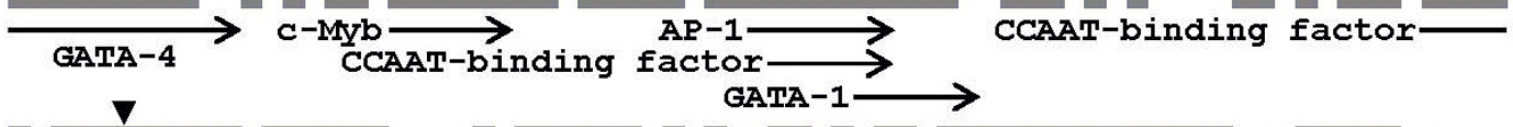

-6 GTTAGTIACACGGCGGTTAGTCATTGAATATCATCACAGTGAAATGTAGAAGTCACTTGAGTTGTCGCC $\rightarrow \quad$ Sp1 $\underset{\mathrm{AP}-1}{\longrightarrow} \stackrel{\mathrm{GATA}-1}{\rightarrow} \underset{\mathrm{CR}-\mathrm{MYb} \longrightarrow}{\longrightarrow} \longrightarrow$

+66 TGAAAGGCTTATTGTGGCGTTGACGTCAGAACAGAACATTATCCAGACGGA

$$
\mathrm{GR} / \mathrm{PR} \underset{\mathrm{GR} / \mathrm{AR} \longrightarrow}{\longrightarrow}
$$

\section{Figure 5}

The 5'-flanking sequence of omTERT. Numbers on the left denote the nucleotide positions relative to the transcription start site (designated as $+I$ and indicated by an inverted triangle). Positions of putative transcription factor binding sites are marked with arrows underneath. The 177-bp sequence in the omTERT promoter which is conserved also in the 5 '-flanking sequence of the $O$. latipes TERT promoter is shaded in gray. 


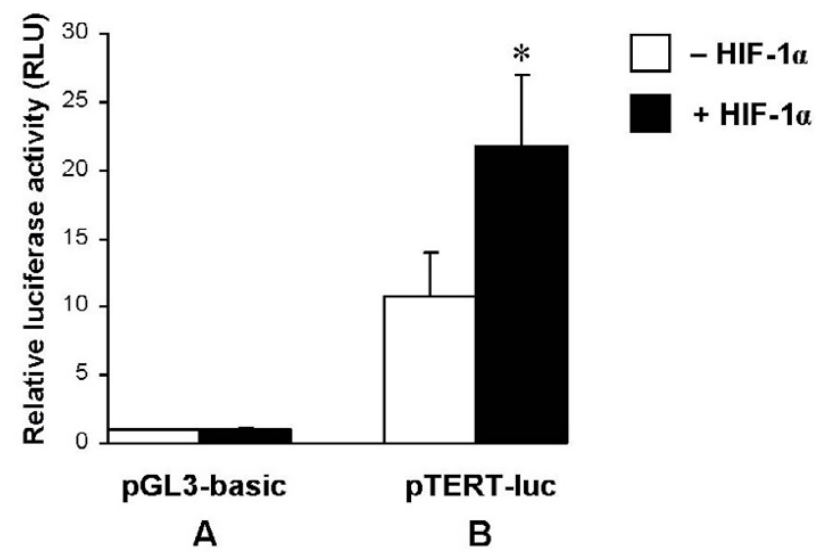

Figure 6

Effect of omHIF-I $\alpha$ overexpression on omTERT promoter activity. $\mathrm{CHO} \mathrm{KaI} 3$ cells were transiently transfected with $600 \mathrm{ng}$ of a luciferase reporter vector containing $3.5 \mathrm{~kb}$ of omTERT 5'-flanking sequence (PTERT-luc; panel B) or $600 \mathrm{ng}$ of empty reporter vector ( $\mathrm{PGL3}$-basic; panel $\mathrm{A}$ ) along with $100 \mathrm{ng}$ of PCMV-omHIF-I $\alpha$ (solid bar) or $100 \mathrm{ng}$ of the empty PCMVTNT vector (open bar) and $100 \mathrm{ng}$ of the pTracer-EF/Bsd/lacZ ( $\beta$-galactosidase) expression vector. Relative luciferase activity (RLU) is the ratio of luciferase over $\beta$-galactosidase activity. Data are the mean \pm SD of three independent experiments. Asterisk $\left(^{*}\right)$ indicates significant effect $(p<0.00 I)$ of omHIF-I $\alpha$ overexpression on induction of pTERT-luc activity.

\section{Discussion}

The marine medaka, O. melastigma, is a hypoxia-tolerant species and can survive in a hypoxic environment (containing $0.8-1.8 \mathrm{mg} \mathrm{O}_{2} / \mathrm{l}$ ) for $1-12$ weeks with $<10 \%$ mortality (Au et al., unpublished observation). The hypoxia tolerance of $O$. melastigma was found to be comparable to that of other hypoxia-tolerant fish species such as the mudsucker, Gillichthys mirabilis [11] and the common carp, Cyprinus carpio [35]. In this study, we have cloned and characterized the expression pattern of the full-length telomerase reverse transcriptase (omTERT) cDNA from the marine medaka, O. melastigma. The deduced omTERT protein contains all of the functional motifs that are conserved in other vertebrate TERTs (Table 1), and shares particularly high sequence identity with the TERT of Fugu (61\%) and moderate sequence identity (29-35\%) with TERTs from other vertebrate species. Among the different motifs in TERT, motif $\mathrm{E}$ is the most highly conserved showing 90.9-100\% overall identity among the fish TERTs and $63.6 \%$ overall identity among vertebrates (Table 1). Banik et al. [25] showed that the sequence spanning motif E to motif E-I is required for telomerase activity and curiously, analysis of the DNA sequences of the fish TERTs in this study showed that the lengths of motifs 1 and 2 (within the RT domain) are shorter by 3 and 8-11 residues, respectively, than other vertebrate TERTs. However, it is unclear what effect these changes may have on the RT activity of TERT. Overall, the findings of this study indicate that the structure and regulation of TERT is highly conserved in vertebrates from fish to human.

Real-time PCR analysis showed that omTERT is expressed ubiquitously, albeit at varying levels, in different organs of the adult marine medaka (Fig. 2). In particular, major expression of omTERT was detected in ovary and testis where germ cells are actively dividing and differentiating. In situ hybridization analysis of testes demonstrated that high omTERT expression is restricted to highly proliferating sperm cells (i.e. spermatogonia and spermatocytes) and differentiating spermatids but not in mature spermatozoa (Fig. 4D). This is in agreement with the findings of Achi et al. [36], which indicated a progressive decline in telomerase activity in the rat testes during sperm cell development. In this context, it was not surprising that omTERT was also found to be highly expressed in regenerative tissues such as gill, gut and kidney. A similarly high level of omTERT expression that was observed in the medaka brain (Fig. 2) may be attributed to the presence of undifferentiated neuronal precursor cells as was demonstrated in the Xenopus brain [37]. Recent evidence indicate that TERT expression in the brain enhances cell survival of developing neurons $[17,18]$. In this study, a low level of omTERT expression was also detected in liver and muscle tissues of the marine medaka. This is in agreement with the presence of telomerase activity in the muscle and liver tissues of adult zebrafish [38], rainbow trout [39] and marine medaka (Au et al., unpublished data).

Marine medaka exposed to prolonged hypoxia showed significant induction of omTERT expression in the testis (96 h) and liver (48 h), as determined by both quantitative RT-PCR and in situ hybridization techniques, that positively correlated with elevated expression levels of the omHIF- $1 \alpha$ and omEpo genes $(p<0.05$; Figs. 3B and 3C, respectively). Because of the unavailability of omHIF- $1 \alpha-$ specific antibodies, detection of omHIF- $1 \alpha$ protein by either Western blotting or immunohistochemistry was not possible, and expression of omHIF-1 $\alpha$ and the HIF-1regulated omEpo gene was therefore used as an indicator of hypoxic induction of omHIF-1 in this study. To determine whether omTERT is responsive to the HIF transcription factor, two putative HRE core sequences (ACGTG) were identified in the omTERT promoter by computer analysis (Fig. 5), and gene transfection experiments in $\mathrm{CHO}$ cells indicated that the omTERT promoter is upregulated by omHIF-1 $\alpha$ (Fig. 6). The results strongly suggest that omHIF- $1 \alpha$ has a role in the regulation of omTERT expression. And based on the molecular responses of omTERT to hypoxia in the medaka liver and testis (Figs. 3 and 4), it is highly likely that upregulated expression of omTERT 
under hypoxia is mediated (at least in part) via omHIF-1 in whole fish in vivo. The mechanistic relationships between omHIF-1 $\alpha$ and omTERT (expression at the mRNA and protein levels), and the associated changes in omTERT telomerase activity in various fish organs under normoxia and hypoxia (and upon normoxic recovery) are currently being investigated in our laboratory to better understand the role(s) of these molecules in cell proliferation and growth.

The differential responses of hepatocytes (in caudal region of the liver) and testicular cells (in spermatogonia) in the marine medaka to hypoxic stress indicate that hypoxic induction of TERT is cell-type specific. Anti-apoptotic and protective functions of TERT against hypoxia-induced apoptosis and DNA damage have been demonstrated in a variety of mammalian cells (see review by Chung et al. [20]). It is tempting therefore to speculate that the increase in omTERT expression in medaka liver and testis under hypoxia could be a protective response to enhance survival of specific cell types. For instance, the role of TERT in maintaining the genomic stability of male germ cells is particularly critical during spermatogenesis to ensure the transfer of intact chromosomes to the offspring [36]. Additionally, the presence of a putative E-box (to which the c-Myc/Max heterodimer could potentially bind) and c-Myb binding sites in the omTERT promoter suggests that omTERT activation may aid in promoting cell proliferation and differentiation $[40,41]$ by counteracting the potentially adverse effects of hypoxia on fish tissues. The molecular mechanisms operating through TERT in regulating cellular homeostasis and gametogenesis in fish certainly warrant further investigation. Functional studies and exposure experiments are currently underway in our laboratory to investigate the significance of the estrogen(EREs) and dioxin-responsive (DREs) elements in the omTERT promoter on in vivo gene expression in the marine medaka. Conceivably, if omTERT expression is responsive to challenges by various estrogenic and/or dioxin-related pollutants, and the responses could be linked to Darwinian fitness traits (such as cell proliferation, growth and reproduction) in the marine medaka, this will open the possibility of TERT being used as a novel and meaningful molecular biomarker of effects for monitoring environmental stress and pollution in the marine environment [42].

\section{Conclusion}

We report here the isolation and characterization of the omTERT gene from O. melastigma, a potential marine model fish for molecular ecotoxicology. Our findings suggest that hypoxic induction of omTERT expression in nontumor liver and testis in whole fish system may be mediated, in part via the omHIF-1 transcription factor. Data from the marine medaka model suggest that the structure and regulation of TERT gene is conserved in vertebrates from fish to human.

\section{Methods \\ Marine medaka}

The marine medaka, Oryzias melastigma, can complete its entire life cycle in full strength seawater. Ubiquitous somatic telomerase activity was detected in O. melastigma which also exhibits telomere lengths (6-12 kb) resembling those of human tissues (8-15 kb) (Au et al., unpublished data). O. melastigma were purchased from a commercial hatchery in Taiwan and were maintained in $30 \%$ artificial seawater at $5.8 \pm 0.2 \mathrm{mg} \mathrm{O}_{2} \mathrm{~L}^{-1}, 28 \pm 2{ }^{\circ} \mathrm{C}$ in a $14 \mathrm{~h}$ light/10 h dark cycle. For hypoxia exposure experiments, adult fish were used and divided into two groups. The first group was maintained in a hypoxic system at $\left(1.8 \pm 0.2 \mathrm{mg} \mathrm{O}_{2} \mathrm{~L}^{-1}\right)$ and the second group in a normoxic system $\left(5.8 \pm 0.2 \mathrm{mg} \mathrm{O}_{2} \mathrm{~L}^{-1}\right)$ for 24,48 and $96 \mathrm{~h}$. Dissolved oxygen was monitored continuously using dissolved oxygen meters and polarographic probes (ColeParmer 5643-00, Illinois, USA). After the exposure period, adult fish ( $n=5$ for each sex) were sampled and tissues were immediately dissected out, snap-frozen in liquid nitrogen and stored at $-80^{\circ} \mathrm{C}$ until ready to be processed.

\section{RNA extraction and cloning of OMTERT CDNA by degenerate $R T-P C R$}

Total RNA was extracted from fish tissues using the TRIZOL reagent (Invitrogen) according to the manufacturer's instructions. First-strand cDNA was synthesized using 1 $\mu \mathrm{g}$ total RNA, $1.25 \mu \mathrm{L}$ dNTP (10 mM), $2.4 \mu \mathrm{L}$ random hexamer (50 ng/ $\mu \mathrm{L}$ ), $1 \mu \mathrm{L}$ RNaseOUT (40 U; Invitrogen) and $1 \mu \mathrm{L}$ M-MLVRT (H-) (200 U/ $\mu \mathrm{L}$; Promega) in a total volume of $25 \mu \mathrm{L}$ in $1 \times \mathrm{M}$-MLVRT reaction buffer at $42^{\circ} \mathrm{C}$ for $50 \mathrm{~min}$. The reaction was terminated by incubation at $70^{\circ} \mathrm{C}$ for $15 \mathrm{~min}$. Using degenerate primers, fTERT-F ( $5^{\prime}-$ TGGCTGAGCTGATGTGGAA-3'; sense) and fTERT-R (5'TCATAGGCYCCACTCACRTC-3'; antisense), that target two regions highly conserved in the TERT sequences of Fugu (clone S001997 [43]) and rainbow trout (Genbank: CA380121, BX088059), RT-PCR was performed on firststrand cDNAs derived from total RNA of fish intestines. The RT-PCR mixture in $50 \mu \mathrm{L}$ consisted of $3 \mu \mathrm{L}$ of firststrand cDNAs (derived from fish intestinal total RNA), 1 $\mu \mathrm{L}$ of each degenerate primer $(10 \mu \mathrm{M}), 1 \mu \mathrm{L}$ dNTP $(10$ $\mathrm{mM}), 5 \mu \mathrm{L} 10 \times$ PCR Buffer and $1 \mu \mathrm{L} 50 \times$ BD Advantage 2 polymerase mix (BD Biosciences). The PCR profile included heat denaturation at $95^{\circ} \mathrm{C}$ for $2 \mathrm{~min}$ followed by 35 cycles of heat denaturation at $95^{\circ} \mathrm{C}$ for $15 \mathrm{~s}$, annealing at $55^{\circ} \mathrm{C}$ for $30 \mathrm{~s}$ and extension at $72^{\circ} \mathrm{C}$ for $1 \mathrm{~min}$.

\section{Rapid amplification of cDNA ends (RACE)}

The full-length omTERT cDNA was obtained from poly $\left(\mathrm{A}^{+}\right)$-selected RNA of whole fish by $5^{\prime}$ - and 3 '-RACE 
PCR using the Marathon cDNA Amplification kit (BD Biosciences). Nested PCR was performed using adaptor-specific primers, AP1 (5'-ATCAGGTCAGACAGCTGTGGGA3'; outer) and AP2 (5'-ACTCACTATAGGGCTCGAGCGGC-3'; inner), along with two gene-specific primers (GSPs). The antisense GSPs for 5'-RACE were omTERT5RACE-R1 (5'-aggagggacggcatggagcgcacac-3'; outer) and omTERT-5RACE-R2 (5'-gtctgccctgatgacccgagtgatgg-3'; inner) whereas the sense GSPs for 3'-RACE were omTERT3RACE-F1 (5'-ggctttgttgtgggcctggtccagg-3', outer) and omTERT-3RACE-F2 (5'-gatcaggtggcgtccctccccaaagac-3', inner). A $50-\mu \mathrm{L}$ PCR reaction contained $5 \mu \mathrm{L} 10 \times$ PCR buffer, $1 \mu \mathrm{L}$ dNTP $(10 \mathrm{mM}), 1 \mu \mathrm{L}$ GSP $(10 \mu \mathrm{M}), 1 \mu \mathrm{L}$ adaptor primer $(10 \mu \mathrm{M}), 5 \mu \mathrm{L} 1: 50$ diluted adaptor-ligated cDNA library (for primary PCR) or 1:50 diluted primary PCR product (for secondary PCR) and $1 \mu \mathrm{L} 50 \times \mathrm{BD}$ Advantage 2 polymerase mix (BD Biosciences). The amplification profile for both primary and secondary PCRs consisted of 5 cycles of $94^{\circ} \mathrm{C}$ for $15 \mathrm{~s}$ and $72^{\circ} \mathrm{C}$ for $3 \mathrm{~min}, 5$ cycles of $94^{\circ} \mathrm{C}$ for $15 \mathrm{~s}$ and $70^{\circ} \mathrm{C}$ for $3 \mathrm{~min}$, and 25 cycles of $94^{\circ} \mathrm{C}$ for $15 \mathrm{~s}$ and $68^{\circ} \mathrm{C}$ for $3 \mathrm{~min}$. Amplification products were purified and cloned into the pGEMTEasy vector (Promega) for DNA sequencing. The fulllength omTERT cDNA was obtained by full-length RT-PCR with primers targeting the cDNA ends using the PfuUltra DNA Polymerase (Stratagene).

\section{Real-time PCR}

Real-time PCR was performed on the iCycler iQ Real-time PCR System (BioRad) using the SYBR Green I dye-based detection method. Similar protocols were also employed to quantify mRNA expression for two hypoxia marker genes, omHIF-1 $\alpha$ and the erythropoietin gene (omEpo). First-strand cDNA was diluted to $1 / 10$ and $5 \mu \mathrm{L}$ were used for each real-time PCR reaction. Triplicates were run for PCR reaction. To normalize the target gene expression for differences in cDNA input, cDNA was diluted 1:2500 for measuring $18 \mathrm{~S}$ rRNA levels. Diluted cDNAs $(5 \mu \mathrm{L}$ aliquots) were added to the wells of a 96-well thin-wall PCR plate, and to each was added $20 \mu \mathrm{L}$ PCR master mix containing $12.5 \mu \mathrm{L} 2 \times$ iQ SYBR Green Supermix (BioRad), $0.5 \mu \mathrm{L}$ of each target gene primer $(10 \mu \mathrm{M})$ and $6.5 \mu \mathrm{L}$ water or $1 \mu \mathrm{L}$ of each $18 \mathrm{~S}$ rRNA primer $(10 \mu \mathrm{M})$ and 5.5 $\mu \mathrm{L}$ water. PCR primers were designed using the Primer3 program [44] and their sequences are shown in Table 2. The PCR plate was heated at $95^{\circ} \mathrm{C}$ for 2 min followed by
40 cycles of $95^{\circ} \mathrm{C}$ for $20 \mathrm{~s}, 60^{\circ} \mathrm{C}$ for $30 \mathrm{~s}$ and $72^{\circ} \mathrm{C}$ for 30 s. For quantification of PCR results, $\mathrm{C}_{\mathrm{T}}$ (the cycle at which the fluorescence signal is significantly different from background) was determined for each reaction. From a standard curve showing the relationship between the quantity of starting material (a dilution series of fish testis cDNA) and $\mathrm{C}_{\mathrm{T}}$, PCR efficiency of the omTERT expression assay was determined to be $98.6 \%\left(\mathrm{R}^{2}=0.999\right)$. Melting-curve analysis was performed by running a heat-dissociation protocol after the PCR to differentiate between the desired target amplicons and any primer-dimers or DNA contaminants. The size and identity of each gene amplicon were verified by agarose gel-electrophoresis and DNA sequencing, respectively. The $\mathrm{C}_{\mathrm{T}}$ values for both reference and target genes, and the efficiencies ( $\mathrm{E}=10-1 /$ slope $)$ of both assays were substituted into Equation (1) to yield the mean normalized expression (MNE) value.

$\mathrm{MNE}=\frac{\left(\mathrm{E}_{\text {reference }}\right)^{\mathrm{C}_{\mathrm{T} \text { reference, mean }}}}{\left(\mathrm{E}_{\text {target }}\right)^{\mathrm{C}_{\mathrm{T} \text { target, mean }}}}$

To calculate the relative fold-change in target gene expression, the MNE of the experimental sample was divided by the MNE of the control (Equation 2).

Relative fold-change $=\mathrm{MNE}_{\exp } / \mathrm{MNE}_{\mathrm{con}}$

\section{Cloning of the 5 '-flanking promoter sequence by genome walking}

A 3.4-kb 5'-flanking sequence of the omTERT gene was obtained using the Genome Walker kit (BD Biosciences) according to the manufacturer's instructions. Briefly, four genomic libraries were obtained by digestion of $O$. melastigma DNA with DraII, EcoRV, PvuII and StuI restriction enzymes and subsequent ligation with an adaptor to the ends of the genomic fragments. Nested PCR amplifications were performed using two adaptor-specific primers provided in the kit, GW-AP1 (outer) and GW-AP2 (inner), in conjunction with two antisense GSPs, omTERT-5GWGSP1 (5'-ACTGTCGGAAGGTTGGAGCAGAGTGG-3'; outer) and omTERT-5GW-GSP2 (5'-AGCGTCTGCGTGCGTTTGTACAGCGAC-3'; inner). A 50- $\mu \mathrm{L}$ PCR reaction contained $5 \mu \mathrm{L} 10 \times$ PCR buffer, $1 \mu \mathrm{L}$ dNTP $(10 \mathrm{mM}), 1$ $\mu \mathrm{L}$ GSP $(10 \mu \mathrm{M}), 1 \mu \mathrm{L}$ adaptor primer $(10 \mu \mathrm{M}), 5 \mu \mathrm{L} 1: 50$

Table 2: Primers used in real-time PCR

\begin{tabular}{|c|c|c|c|c|}
\hline Gene & Sense primer & Antisense primer & Amplicon size (bp) & $\begin{array}{c}\text { Genbank accession } \\
\text { number }\end{array}$ \\
\hline omTERT & 5'-CTGATGTGGAAGATGAAGGTGA-3' & 5'-AGAAGCCAGGTCAGAAACAGAC-3' & 122 & DQ286654 \\
\hline omEPO & 5'-GACCGGCTTGTGGCTGTT-3' & 5'-CGTGTTGGTGACCGATGGT-3' & 61 & $\overline{\mathrm{DQ} 415657}$ \\
\hline omHIFI $\alpha$ & 5'-TGTGATATTTGGAGCATTCCA-3' & 5'-CTACGACAGGAAATCCCATGA-3' & 115 & DQ317443 \\
\hline I8S rRNA & 5'-CCTGCGGCTTAATTTGACCC-3' & 5'-GACAAATCGCTCCACCAACT-3' & 134 & DQ105650 \\
\hline
\end{tabular}


diluted adaptor-ligated genomic library (for primary PCR) or 1:50 diluted primary PCR product (for secondary PCR) and $1 \mu \mathrm{L} 50 \times$ BD Advantage 2 polymerase mix (BD Biosciences). The amplification profile used was the same as that in RACE-PCR.

\section{Plasmid constructs}

The omTERT 5'-flanking region (nt. +48/- 3428; the transcription start site is defined as +1 ) was PCR amplified using primers with built-in restriction sites, TERTp-lucF (5'- AGACGCGTGGGGAAATTTGGAGTAACTG-3'; MluI site is underlined) and TERTp-lucR (5'-AA CTCGAGCAGGCGACAACTCAAGTGAC-3'; XhoI site is underlined). The PCR fragment (ca. 3.5-kb) was double digested with MluI/ XhoI and subcloned into the pGL3-basic luciferase reporter vector (Promega) to produce pTERT-luc. The pCMV-omHIF-1 $\alpha$ expression vector was generated by RTPCR cloning of the coding region of omHIF-1 $\alpha$ (DQ317443) using primers omHIF1 $\alpha-F$ (5'-AACTCGAGCCTGACATGGACACAGGATTCGTACC-3'; XhoI site is underlined) and omHIF1a-R (5'-GTACGCGTTAACTGACTCAGATGACGTGGTCCAACG-3'; MluI site is underlined). The 2.2-kb RT-PCR product was subcloned into the XhoI/MluI site of the pCMV-TNT expression vector (Promega). All constructs were verified by automated DNA sequencing.

\section{Cell transfection and luciferase reporter assay}

Materials for cell culture and transfection were obtained from Invitrogen, unless specified otherwise. The HIF- $1 \alpha-$ deficient Chinese hamster ovary cell line (CHO Ka13) was a gift from Professor Peter Ratcliffe (Wellcome Trust Center for Human Genetics, Oxford University, UK). Cells were cultured in DMEM supplemented with $10 \%$ fetal calf serum, $1 \%$ antibiotics (penicillin G, $100 \mathrm{U} / \mathrm{mL}$; streptomycin, $100 \mu \mathrm{g} / \mathrm{mL}$ ) and $0.1 \mathrm{mM}$ non-essential amino acids, in humidified air containing $5 \% \mathrm{CO}_{2}$ at $37^{\circ} \mathrm{C}$. $\mathrm{CHO}$ Ka13 cells seeded in 24-well plates at $1.1 \times 10^{5}$ cells per well were transfected with 600 ng of pTERT-luc or pGL3basic reporter vector, $100 \mathrm{ng}$ pCMV-omHIF- $1 \alpha$ or pCMVTNT expression vector and 100 ng pTracer-EF/Bsd/lacZ ( $\beta$-galactosidase expression vector) in LipofectAMINE 2000 and Opti-MEM reduced serum medium. After $18 \mathrm{~h}$, cells were harvested with Glo-lysis buffer (Promega). Luciferase and $\beta$-galactosidase activities were measured using a Bright-Glo Luciferase Assay System (Promega) and a Beta-Glo Assay System (Promega), respectively. Interwell variations in transfection efficiency were corrected by normalization to $\beta$-galactosidase activity. Data given are mean \pm SD from three independent experiments with duplicates in each experiment.

\section{In situ hybridization}

In situ hybridization was performed to compare the cellular expression patterns of omTERT in testes and liver of normoxic and hypoxic fish. Briefly, whole fish was fixed in a cocktail of fixatives, dehydrated in a graded methanol series, infiltrated and embedded in paraffin. Serial sagittal sections $(5-\mu \mathrm{m})$ were cut and mounted for in situ hybridization (for details, see [45]). A 300-bp omTERT fragment spanning motif E and motif E-I (nt. 2749-3048; Fig. 1) was cloned into the pGEM-T Easy vector (Promega), and digoxigenin (DIG)-labeled antisense and sense riboprobes were synthesized by in vitro transcription. Hybridization was performed overnight at $50^{\circ} \mathrm{C}$ with DIGlabelled riboprobes $(0.5 \mathrm{ng} / \mu \mathrm{l})$ in $2 \times$ SSC, $50 \%$ formamide, $10 \%$ dextran sulfate, $50 \mu \mathrm{g} / \mathrm{mL}$ yeast tRNA and $5 \mathrm{U} /$ $\mathrm{mL}$ RNase inhibitor. After hybridization, slides were washed in a graded series of SSC- $0.1 \%$ Tween 20 at room temperature and incubated with anti-DIG antibody coupled to alkaline phosphatase (at 1:100 dilution; Roche Applied Science). Signals were detected using the NBT/ BCIP substrate (Zymed). Sections were counterstained with Nuclear Fast Red and then examined by light microscopy (Carl Zeiss, Axioplan 2).

\section{Statistical analysis}

Test for data homogeneity was conducted using Bartlett's test. Two-way analysis of variance (ANOVA) was used to test the null hypothesis that hypoxia does not cause significant changes in omTERT/omHIF-1 $\alpha /$ omEpo gene expressions in testis/liver during the exposure period, and that no temporal changes occur in various gene expressions in testis/liver during the exposure period. Where significant differences were identified $(p<0.05)$ in treatment or in time, pairwise comparisons between the normoxia and hypoxia groups for the same time point, or pairwise comparisons between sampling intervals for the normoxia/ hypoxia groups in testis/liver were carried out using Tukey's test. Likewise, Student's $t$-test was used to test that there was no significant difference in luciferase activities of pTERT-luc transfected cells in the absence/presence of omHIF- $1 \alpha$ overexpression. Differences with $p<0.05$ were considered significant. Statistical analysis was performed using the SigmaStat 3.0.1 package (SYSTAT Software Inc.).

\section{Authors' contributions}

RMKY conducted most of the experimental work and data analyses in this study and drafted the manuscript. EXHC and PKSN performed the in situ hybridization and cell transfection experiments, respectively. HOLM assisted with the expression studies and data analysis. DWTA and RYCK initiated the project idea and contributed to the experimental design and editing of the manuscript.

\section{Acknowledgements}

This study was supported by the University Grants Committee of the Hong Kong Special Administrative Region, China (Project no. AoE/P-04/04) and a CityU grant (Project no. 700 1694). The authors would like to thank Prof. Rudolf $\mathrm{Wu}$ and his team for fish tissue samples, and Gabriel Lam, Michael Chiang, Bill Yip and Prof. P.L. Lim's group for technical assistance. 


\section{References}

I. Greider CW: Telomere length regulation. Annu Rev Biochem 1996, 65:337-365.

2. Krupp G, Bonatz G, Parwaresch R: Telomerase, immortality and cancer. Biotechnol Annu Rev 2000, 6:103-140.

3. Yatabe N, Kyo S, Maida Y, Nishi H, Nakamura M, Kanaya T, Tanaka M, Isaka K, Ogawa S, Inoue M: HIF-I-mediated activation of telomerase in cervical cancer cells. Oncogene 2004, 23:3708-37I5.

4. Nishi H, Nakada T, Kyo S, Inoue M, Shay JW, Isaka K: Hypoxiainducible factor I mediates upregulation of telomerase (hTERT). Mol Cell Biol 2004, 24:6076-6083.

5. Anderson CJ, Hoare SF, Ashcroft M, Bilsland AE, Keith WN: Hypoxic regulation of telomerase gene expression by transcriptional and post-transcriptional mechanisms. Oncogene 2006, 25:61-69.

6. Seimiya H, Tanji M, Oh-hara T, Tomida A, Naasani I, Tsuruo T: Hypoxia up-regulates telomerase activity via mitogen-activated protein kinase signaling in human solid tumor cells. Biochem Biophys Res Commun 1990, 260:365-370.

7. Koshiji M, Kageyama Y, Pete EA, Horikawa I, Barrett JC, Huang LE: HIF-I $\alpha$ induces cell cycle arrest by functionally counteracting Myc. EMBO J 2004, 23: 1949-1956.

8. Nixon SW: Ambio Special Issue: Marine Eutrophication. Ambio 1990, 19:101-176.

9. Diaz RJ, Rosenberg R: Marine benthic hypoxia: A review of its ecological effects and the behavioral responses of benthic macrofauna. Oceanogr Mar Biol 1995, 33:245-303.

10. Wu RSS: Hypoxia: from molecular responses to ecosystem responses. Mar Pollut Bull 2002, 45:35-45.

II. Gracey AY, Troll JV, Somero GN: Hypoxia-induced gene expression profiling in the euryoxic fish Gillichthys mirabilis . Proc Natl Acad Sci USA 2001, 98:1993-1998.

12. Storey KB: Suspended animation: The molecular basis of metabolic depression. Can J Zool 1988, 66:124-132.

13. Hochachka PW, Buck LT, Doll C), Land SC: Unifying theory of hypoxia tolerance: molecular/metabolic defense and rescue mechanisms for surviving oxygen lack. Proc Natl Acad Sci USA 1996, 93:9493-9498.

14. Hochachka PW: Oxygen-a key regulatory metabolite in metabolic defense against hypoxia. Am Zool 1997, 37:595-603.

I5. Kajimura S, Aida K, Duan C: Insulin-like growth factor-binding protein-I (IGFBP-I) mediates hypoxia-induced embryonic growth and developmental retardation. Proc Natl Acad Sci USA 2005, I 02: I 240-1245.

16. Kajimura S, Aida K, Duan C: Understanding hypoxia-induced gene expression in early development: in vitro and in vivo analysis of hypoxia-inducible factor I-regulated zebra fish insulin-like growth factor binding protein I gene expression. Mol Cell Biol 2006, 26: I I42-I I 55.

17. Fu W, Killen M, Culmsee C, Dhar S, Pandita TK, Mattson MP: The catalytic subunit of telomerase is expressed in developing brain neurons and serves a cell survival-promoting function. J Mol Neurosci 2000, I4:3-I5.

18. Fu W, Lu C, Mattson MP: Telomerase mediates the cell survival-promoting actions of brain-derived neurotrophic factor and secreted amyloid precursor protein in developing hippocampal neurons. I Neurosci 2002, 22: 10710-10719.

19. Smith LL, Coller HA, Roberts JM: Telomerase modulates expression of growth-controlling genes and enhances cell proliferation. Nat Cell Biol 2003, 5:474-479.

20. Chung HK, Cheong C, Song J, Lee HW: Extratelomeric functions of telomerase. Curr Mol Med 2005, 5:233-24I.

21. Yap WH, Yeoh E, Brenner S, Venkatesh B: Cloning and expression of the reverse transcriptase component of pufferfish (Fugu rubripes) telomerase. Gene 2005, 353:207-217.

22. Lingner J, Hughes TR, Shevchenko A, Mann M, Lundblad V, Cech TR: Reverse transcriptase motifs in the catalytic subunit of telomerase. Science 1997, 276:56 I-567.

23. Xia J, Peng Y, Mian IS, Lue NF: Identification of functionally important domains in the $\mathbf{N}$-terminal region of telomerase reverse transcriptase. Mol Cell Biol 2000, 20:5196-5207.

24. Kuramoto $M$, Ohsumi $K$, Kishimoto $T$, Ishikawa F: Identification and analyses of the Xenopus TERT gene that encodes the catalytic subunit of telomerase. Gene 200I, 277:I0I-I I0.

25. Banik SS, Guo C, Smith AC, Margolis SS, Richardson DA, Tirado CA, Counter CM: C-terminal regions of the human telomerase catalytic subunit essential for in vivo enzyme activity. Mol Cell Biol 2002, 22:6234-6246.

26. Delany ME, Daniels LM: The chicken telomerase reverse transcriptase (chTERT): molecular and cytogenetic characterization with a comparative analysis. Gene 2004, 339:6 I-69.

27. Nakamura TM, Morin GB, Chapman KB, Weinrich SL, Andrews WH, Lingner J, Harley CB, Cech TR: Telomerase catalytic subunit homologs from fission yeast and human. Science 1997 , 277:955-959.

28. Weinrich SL, Pruzan R, Ma L, Ouellette M, Tesmer VM, Holt SE, Bodnar AG, Lichtsteiner S, Kim NW, Trager JB, Taylor RD, Carlos R, Andrews WH, Wright WE, Shay JW, Harley CB, Morin GB: Reconstitution of human telomerase with the template RNA component hTR and the catalytic protein subunit hTRT. Nat Genet 1997, 17:498-502.

29. Horikawa I, Cable PL, Afshari C, Barrett JC: Cloning and characterization of the promoter region of human telomerase reverse transcriptase gene. Cancer Res 1999, 59:826-830.

30. PromoterWise program (EMBL-EBI) [http://www.ebi.ac.uk/
[ Wise2/promoterwise.html]

31. Medaka genome project (NIG DNA Sequencing Center, Japan) [http://dolphin.lab.nig.ac.jp/medaka/]

32. TESS: Transcription Element Search System [http:// www.cbil.upenn.edu/cgi-bin/tess/tess]

33. Cong YS, Wright WE, Shay JW: Human telomerase and its regulation. Microbiol Mol Biol Rev 2002, 66:407-425.

34. Takakura M, Kyo S, Inoue M, Wright WE, Shay JW: Function of AP$I$ in transcription of the telomerase reverse transcriptase gene (TERT) in human and mouse cells. Mol Cell Biol 2005, 25:8037-8043.

35. Wu RSS, Zhou BS, Randall DJ, Woo NYS, Lam PKS: Aquatic hypoxia is an endocrine disrupter and impairs fish reproduction. Environ Sci Technol 2003, 37: I I37-1141.

36. Achi MV, Ravindranath N, Dym M: Telomere length in male germ cells is inversely correlated with telomerase activity. Biol Reprod 2000, 63:591-598.

37. Kara TC: Ageing in amphibians. Gerontology 1994, 40:161-173.

38. Kishi S, Uchiyama J, Baughman AM, Goto T, Lin MC, Tsai SB: The zebrafish as a vertebrate model of functional aging and very gradual senescence. Exp Gerontol 2003, 38:777-786.

39. Klapper W, Heidorn K, Kuhne K, Parwaresch R, Krupp G: Telomerase activity in 'immortal' fish. FEBS Lett I998, 434:409-4I2.

40. Walhout AJ, Gubbels JM, Bernards R, van der Vliet PC, Timmers HT: c-Myc/Max heterodimers bind cooperatively to the E-box sequences located in the first intron of the rat ornithine decarboxylase (ODC) gene. Nucleic Acids Res 1997, 25:|493-I50I.

41. Ness SA: Myb binding proteins: regulators and cohorts in transformation. Oncogene 1999, 18:3039-3046.

42. Au DWT: The application of histo-cytopathological biomarkers in marine pollution monitoring: a review. Mar Pollut Bull 2004, 48:817-834.

43. The Fugu Informatics Network [http://fugu.biology.qmul.ac.uk/]

44. Primer3 [http://frodo.wi.mit.edu/cgi-bin/primer3/ primer3 www.cgi]

45. Chen $\mathrm{EXH}, \mathrm{Yu}$ RMK, Chiang MWL, Lim PL, Au DWT: Relating telomerase expression to cell proliferation in whole medaka fish in vivo. In Proceedings of the Fifth Intercongress Symposium of the Asia and Oceania Society for Comparative Endocrinology: 7-10 February 2006; Bangkok Edited by: Prakong Tangpraprutgul et al.: Chulalongkorn University;; 2006: I29-133. 